Title:

\title{
Photoredox Reactions: Energy Storage and Halocarbon Degradation
}

\author{
Author(s): William H. Woodruff, CST-4 \\ R. Brian Dyer, CST-4 \\ Harry B. Gray, Cal. Tech.
}

\author{
REOENED \\ JUL 251997
}

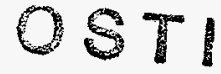

\section{Submitted to: DOE Office of Scientific and Technical Information (OSTI)}

\section{DISCLAIMER}

This report was prepared as an account of work sponsored by an agency of the United States Government. Neither the United States Government nor any agency thereof, nor any of their employees, makes any warranty, express or implied, or assumes any legal liability or responsibility for the accuracy, completeness, or usefulness of any information, apparatus, product, or process disclosed, or represents that its use would not infringe privately owned rights. Reference herein to any specific commercial product, process, or service by trade name, trademark, manufacturer, or otherwise does not necessarily constitute or imply its endorsement, recommendation, or favoring by the United States Government or any agency thereof. The views and opinions of authors expressed herein do not necessarily state or reflect those of the United States Government or any agency thereof.

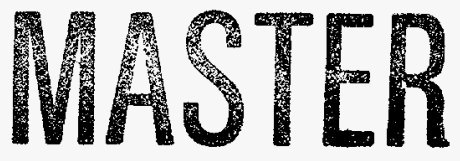

\section{Los Alamos}

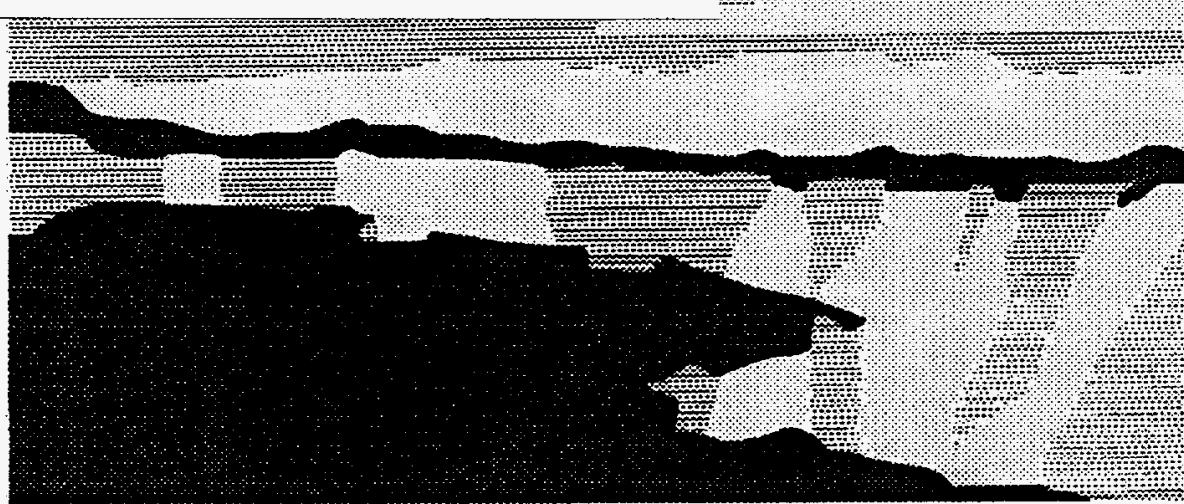

NATIONAL LABORATORY

Los Alamos National Laboratory, an affirmative action/equal opportunity employer, is operated by the University of Califomia for the U.S. Departmenl of Energy under contract W-7405-ENG-36. By acceptance of this article, the publisher recognizes that the U.S. Government retains a nonexclusive, royaltyfree license to publish or reproduce the published form of this contribution, or to allow others to do so, for U.S. Government purposes. The Los Alamos Nalional Laboratory requests that the publisher identify this article as work performed under the auspices of the U.S. Department of Energy. 


\section{DISCLAMMER}

Portions of this document may be illegible in electronic image products. Images are produced from the best available original document. 


\title{
Photoredox Reactions: Energy Storage and Halocarbon Degradation
}

\author{
William H. Woodruff amd R. Brian Dyer \\ Los Alamos National Laboratory \\ Harry B. Gray \\ California Institute of Technology
}

\begin{abstract}
This is the final report of a three-year, Laboratory Directed Research and Development (LDRD) project at the Los Alamos National Laboratory (LANL). The objectives of this project were the following. (1) To characterize the structures and the structural dynamics of the singlet and triplet states of selected metal-metal bonded systems. (2) To characterize the post-excitation intramolecular electron transfer reactions of these complexes. (3) To investigate strongly adiabatic photo-oxidative addition reactions, including the addition of halocarbons to the electronically excited complexes and their hydrogen-evolving reactions. (4) To seek effective reductant systems that will function in catalutic cycles and regenerate the original, reduced dimer. (5) To explore the chemistry of metals less expensive than iridium or platinum with regard to their potential for photochemical reactivity. The results include studies of $\mathrm{W}$ and Mo clusters with potential multielectron excited state redox reactivity, metal-metal bonded dimers sequestered in liquid crystal environments, $d^{7}$ dimers with long-lived photocycles, and photochemically produced oxygen-fluorine systems. The results have been reported in four research articles, two published in Inorganic Chemistry and one each in Inorganica Chimica Acta and Journal of Fluorine Chemistry.
\end{abstract}

\section{Background and Research Objectives}

Redox reactions comprise one of the most important and widespread classes of chemical phenomena. They lie at the basis of innumerable fundamental and practical chemical processes. A few broad examples include energy conversion and storage (e.g. fuel production, combustion, photochemistry, electrochemistry), catalysis, bioenergetics (e.g. respiration and photosynthesis), and the biological and environmental degradation of toxic substances.

The basic processes that occur during redox reactions encompass an enormous range of behavior. On the one hand stands simple electron transfer, where the critical difference between

*Principal Investigator, e-mail: woody@lanl.gov 
the reactants and products is the transfer of an electron from a donor $D$ to an acceptor $A$ which otherwise retain their molecular identities (i.e. $D+A \rightarrow D^{+}+A^{-}$). This is the only type of chemical reaction that can occur without formation or breaking of bonds. On the other end of the scale of redox behavior stand "strongly adiabatic" reactions wherein bond making and breaking are integral with changes in oxidation state such that there is no discrete, identifiable electron transfer step. A simple example is $\mathrm{I}_{2}+\mathrm{OH}^{-} \rightarrow \mathrm{HOI}+\mathrm{I}^{-}$, in which iodine unquestionably undergoes a change in oxidation state but the character of the reaction may equally well be regarded as acid-base or oxidative addition-reductive elimination.

Photoredox reactions comprise a special case involving redox reactions of molecules which have been electronically excited by the absorption of light. They offer special opportunities for the conversion of light into chemical energy by photochemically driving reactions that are thermodynamically unfavorable in the ground state, and for photocatalysis of reactions that are thermodynamically favorable but normally slow. The subclass of intramolecular photoredox reactions offers a unique opportunity to observe, and test theoretical predictions of, electron transfer (ET) reactivity in the absence of complicating factors, most notably the requirement for reactants to diffuse together.

An intriguing class of intramolecular photoredox syslems are based on metal-metal bonded dimers and clusters. There are several unique aspects of the chemistry of such complexes, one of the most distinctive being the ability (in principle) to undergo multi-electron excited state redox chemistry. Two important issues arise with respect to the photoreactivity of these complexes. The first concerns energy conversion schemes based on photoinitiated electron transfer. In these schemes, a central problem is how to achieve kinetic stabilization of the charge-separated product with respect to the original ground-state reactants, which are the thermodynamically stable species. The second issue is concerned with tests of electron transfer theory. These issues are related in that the "inverted region" represents a possible way to capture the energy of photoexcitation and suppress losses due to the thermal back reaction.

An aspect of the photochemistry of the $d^{8}$ dimers is their ability to photoactivate and cleave halocarbons as well as other organic species. This type of photoreactivity is a common theme for $\mathrm{d}^{8}$ dimers. The photochemistry leads to oxidative addition of halocarbon fragments to the dimer as shown below:

$$
\begin{aligned}
& \mathrm{RX}+(\mathrm{L} 1)(\mathrm{L} 2) \operatorname{Ir} 2(\mathrm{I}, \mathrm{I})(\mathrm{L} 3)(\mathrm{L} 4)+\text { light } \rightarrow(\mathrm{R})(\mathrm{L} 1)(\mathrm{L} 2) \operatorname{Ir} 2(\mathrm{II}, \mathrm{II})(\mathrm{L} 3)(\mathrm{L} 4)(\mathrm{X}), \text { or } \\
& 2 \mathrm{RX}+(\mathrm{L} 1)(\mathrm{L} 2) \operatorname{Ir} 2(\mathrm{I}, \mathrm{I})(\mathrm{L} 3)(\mathrm{L} 4)+\text { light } \rightarrow(\mathrm{X})(\mathrm{L} 1)(\mathrm{L} 2) \operatorname{Ir} 2(\mathrm{II}, \mathrm{II})(\mathrm{L} 3)(\mathrm{L} 4)(\mathrm{X})+\mathrm{R} 2 .
\end{aligned}
$$


These photo-oxidative additions are excellent examples of "strongly adiabatic" photoredox reactions, and are worthy of study simply because experimental understanding of these processes is poor. There are more practical reasons for wishing to study these particular reactions, however. Halocarbons are of serious concern as important and widespread environmental contaminants. It should be possible to design a photocatalytic cycle for halocarbon degradation wherein the net reaction is, for example:

$$
\mathrm{RX}+\mathrm{H}_{2} \rightarrow \mathrm{RH}+\mathrm{HX}
$$

Such a photocatalytic cycle may be of great importance in practical environmental remediation or minimization strategies.

The objectives of this project were the following. (1) To characterize the structures and the structural dynamics of the singlet and triplet states of selected metal-metal bonded systems. (2) To characterize the post-excitation intramolecular electron transfer reactions of these complexes. (3) To investigate strongly adiabatic photo-oxidative addition reactions, including the addition of halocarbons to the electronically excited complexes and their hydrogen-evolving reactions. (4) To seek effective reductant systems that will function in catalutic cycles and regenerate the original, reduced dimer. (5) To explore the chemistry of metals less expensive than iridium or platinum with regard to their potential for photochemical reactivity.

\section{Importance to LANL's Science and Technology Base and National R\&D Needs}

A. Tests of the predictions of electron transfer theories either validate the existing predictions or provide an experimental basis for refinements and future theoretical developments. Our particular contributions involve elucidation of the precise structural changes and the identities and roles of the vibrational states that are involved in promoting the dynamics. Only the time-resolved vibrational approaches that we employ can provide this information.

B. We have made progress toward the development of practical devices for the conversion of light into chemical energy. The practical impact of such a device and the technology transfer and commercialization potential is large.

C. We have discovered photocatalytic systems that might be useful for the degradation of halocarbons in the environment. It is clear that there is great technology transfer and CRADA potential for this activity. 


\section{Scientific Approach and Accomplishments}

Our primary research approaches in terms of technique are time-resolved vibrational spectroscopies, including Raman and infrared ( $<1$ ps to arbitrarily long times). These techniques are complementary in several respects. Raman reports molecular vibrations that need not involve a dipole change, while infrared obeys dipolar selection rules. This allows molecular symmetries to be deduced. Raman is particularly suitable for metal-metal bonds, while infrared is the technique of choice for the ligand vibrations that we will use as "reporter modes" for transient structures as described below. Raman allows electronic resonance enhancement, and thus imparts information on the coupling of vibrational and electronic transitions. This is a key to understanding photophysical and electron transfer dynamics. Raman and infrared are also complementary with regard to their applicability to different systems. Regardless of which technique produces them, however, the vibrational data are the key to answering the questions posed. The intramolecular ET studies that are proposed required considerable effort to synthesize the metal-metal bonded complexes. The complexes that are required were acquired through our collaboration with Harry Gray at Caltech, Malcolm Chisholm at Indiana, and Kim Dunbar at Michigan State.

The general approach is to determine the vibrational frequencies of the metal-metal, metal-ligand, and internal ligand motions and thus infer structure, vibrational state, and electronic parameters such as the polarization of the metal-metal bond in the $\sigma * \rightarrow \sigma$ states and the localization or delocalization of valence in the ET states. For the latter purposes, the use of ligand vibrations as "reporters" of the metals' electron density is a key experiment. We have shown that the $\pi$ back-donation properties of the metal are sensitive indicators of effective oxidation state and electronic state, and that these $\pi$ effects can readily be seen in the infrared frequencies of ligands.

Our results include studies of $\mathrm{W}$ and Mo clusters with potential multielectron excited state redox reactivity, metal-metal bonded dimers sequestered in liquid crystal environments, $\mathrm{d}^{7}$ dimers with long-lived photocycles, and photochemically produced oxygen-fluorine systems. Specific results follow.

Resonance Raman spectra of the cubic metal-halide complexes $\left[\mathrm{M}_{6} \mathrm{X}_{8} \mathrm{Y}_{6}\right]^{2-}(\mathrm{M}=\mathrm{Mo}$ or $\mathrm{W} ; \mathrm{X}, \mathrm{Y}=\mathrm{Cl}, \mathrm{Br}$, or I) are reported. The three totally symmetric fundamental vibrations of these complexes are identified. The extensive mixing of the symmetry coordinates that compose the symmetric normal modes expected in these systems is not observed. Instead the group-frequency approximation is valid. The force constants of both the apical and face- 
bridging metal-halide bonds are insensitive to the identity of either the metal or the halide. Raman spectra of related complexes with methoxy and benzenethiol groups as ligands are reported along with the crystal structural data for $\left[\mathrm{Mo}_{6} \mathrm{Cl}_{8}(\mathrm{SPh}) 6\right][\mathrm{NBu} 4]_{2}$.

$\mathrm{Ru}_{2}\left(\mathrm{O}_{2} \mathrm{C}\left(\mathrm{CH}_{2}\right)_{6} \mathrm{CH}_{3}\right)_{4}$ (1a) is soluble in both coordinating (THF, $\mathrm{MeOH}, \mathrm{MeCN}$ ) and noncoordinating solvents (benzene, toluene, cyclohexane, $\mathrm{CH}_{2} \mathrm{Cl}_{2}$ ), allowing its solution properties to be studied by ${ }^{1} \mathrm{H}$ and ${ }^{13} \mathrm{C}$ NMR spectroscopy, UV/visible spectroscopy, resonance Raman spectroscopy, and cyclic voltammetry. In noncoordinating solvents, 1a exists as an oligomer, presumably by way of axial intermolecular interactions. ${ }^{1} \mathrm{H}$ NMR studies of $1 \mathrm{a}$ and $\left[\mathrm{Ru}_{2}\left(\mathrm{O}_{2} \mathrm{C}\left(\mathrm{CH}_{2}\right)_{6} \mathrm{CH}_{3}\right) 4\right]^{+}[\mathrm{X}]^{-}\left([1 \mathrm{a}]^{+}[\mathrm{X}]^{-}\right)$where $\mathrm{X}=\mathrm{Cl}, \mathrm{BF} 4$, or $\mathrm{O}_{2} \mathrm{C}\left(\mathrm{CH}_{2}\right)_{6} \mathrm{CH}_{3}$ indicate that both dipolar and contact mechanisms contribute to the paramagnetic shifts of the protons. Resonances for axial and equatorial ligands are shifted upfield and downfield, respectively, by a dipolar mechanism. Aromatic ligands in the axial sites, e.g. pyridine and pyrazine, experience an enhanced upfield shift by direct $\pi$ delocalization. Comparison of the ${ }^{1} \mathrm{H}$ NMR signals for $\mathrm{M}_{2}\left(\mathrm{O}_{2} \mathrm{CR}\right) 4$ compounds where $\mathrm{M}=$ $\mathrm{Ru}$ and $\mathrm{O}_{2} \mathrm{CR}=$ benzoate, toluate, butyrate, crotonate, and dimethylacrylate with those where $\mathrm{M}=\mathrm{Mo}$ indicates that the equatorial carboxylate ligands in the diruthenium species also experience $\pi$-contact shifts. Variable-temperature studies and calculated estimates of dipolar shifts (using structural parameters taken from solid-state structures) indicate a significant zerofield splitting contribution to the dipolar shift. The arrangement of the toluate rings in $\mathrm{Ru}_{2}\left(\mathrm{O}_{2} \mathrm{C} \text {-p-tolyl }\right)_{4}(\mathrm{THF})_{2}, \mathrm{Ru}_{2}\left(\mathrm{O}_{2} \mathrm{C} \text {-p-tolyl }\right)_{4}(\mathrm{MeCN})_{2}$, and $\left[\mathrm{Ru}_{2}\left(\mathrm{O}_{2} \mathrm{C}\right.\right.$-ptolyl) $\left.4(\mathrm{THF})_{2}\right]^{+}[\mathrm{BF} 4]^{-}$deviate by $15(1), 2.3(2)$, and $7.3^{\circ}$, respectively, from alignment with the Ru-Ru axis. The Ru-Ru distances for the two neutral and the cationic complexes are $2.27(1) \AA$, i.e. not significantly affected by the nature of the axial ligand (THF vs. MeCN) or by charge $n^{+}(n=0,1)$. Crystal structures for these complexes are reported.

Events following the photodissociation of the dinuclear rhodium(II,II) complex $\mathrm{Rh}_{2} \mathrm{~L}_{10}\left(\mathrm{~L}=\mathrm{CH}_{3} \mathrm{CN}\right)$, are reported. Spectroscopic and electrochemical evidence demonstrates that this complex possesses novel reversible photochemistry with metastable photoproducts that exist for kiloseconds after photodissociation, and ultimately regenerate the original dimer. UV/Vis irradiation of acetonitrile solutions of the complex results in homolytic cleavage of the $\mathrm{Rh}-\mathrm{Rh}$ bond to give a promptly formed paramagnetic transient that EPR evidence suggests to be Rh(II)L6. This species has a half-life of approximately $50 \mathrm{~s}$, and initiates a reaction sequence that generates photodisproportionated, metastable products, which are inferred to be $\mathrm{Rh}(\mathrm{III}) \mathrm{L}_{6}$ and $\mathrm{Rh}_{3}(\mathrm{II}, \mathrm{II}, \mathrm{I}) \mathrm{L}_{\mathrm{n}}$. These products have half-lives in the 
kilosecond range. The proposed photochemical processes thus achieve photoinduced charge separation, with remarkably long lifetimes for the charge-separated species. The metastable species may be viewed as a photogenerated electron-hole pair in solution that, due to its long lifetimes, may have significant potential in converting light into usable chemical energy.

The decomposition of gaseous dioxygen difluoride (FOOF) and dioxygen fluoride (FOO) to $\mathrm{F}_{2}$ and $\mathrm{O}_{2}$ at ambient temperature has been studied by EPR spectroscopy, Fouriertransform IR (FT-IR) spectroscopy and transient gas pressure measurements. The formation of oxygen in FOOF/FOO gas mixtures, as demonstrated by stopped-flow EPR, was first-order under low-pressure conditions (1-10 Torr) with rate constants in the range of 0.1-0.2 s-1, depending upon wall materials. EPR spectroscopy detected neither $F$ atoms nor FOO radicals as intermediates despite the presence of FOO radicals shown by complementary FT-IR experiments. The FT-IR spectra of gaseous FOOF undergoing decomposition at ambient temperature showed prominent, isolated bands near $1210 \mathrm{~cm}^{-1}$ (FOOF) and near $1490 \mathrm{~cm}^{-1}$ (FOO). Overlapping bands attributable to both species were seen near $650 \mathrm{~cm}^{-1}$, and weak features appeared elsewhere. At nominal initial FOOF/FOO pressures of 4-20 Torr, results from stopped-flow FT-IR kinetics analysis using these bands generally agreed with the EPR results and yielded first-order rate constants of $0.12 \pm 0.01 \mathrm{~s}-1$ and $0.22 \pm 0.03 \mathrm{~s}^{-1}$, respectively, for FOO and FOOF disappearance. Oxygen-carrier FT-IR experments strongly suggested that a reversible reaction between FOOF and $\mathrm{O}_{2}$ forms FOO (Keq»0.018), and that this reaction was rapid relative to FOOF/FOO decomposition. Analysis of the stopped-flow FT-IR results yielded IR peak absorptivities for FOOF absorption at $1205 \mathrm{~cm}^{-1}$ of $1.8 \pm 0.4^{\prime} 10^{-3}$ (Torr cm) $)^{-1}$ and for FOO absorption at $1486 \mathrm{~cm}^{-1}$ of $3.5 \pm 1^{\prime} 10^{-3}$ (Torr cm) (T. $^{-1}$. The observed kinetics are discussed in terms of the possible decomposition reaction mechanisms. 


\section{Publications}

1. Schoonover, J.; Zietlow, T.; Clark, D.; Heppert, J.; Chisholm, M.; Gray, H.; Sattelberger, A.; Woodruff, W. "Resonance Raman Spectra of [M6X8Y6]2- Cluster Complexes (M=Mo, $\mathrm{W} ; \mathrm{X}, \mathrm{Y}=\mathrm{Cl}, \mathrm{Br}, \mathrm{I})$ ". Inorg. Chem., 35(22), 6606-6613 (1996).

2. Chisholm, M.; Christou, G.; Folting, K.; Huffman, J.; James, C.; Samuels, J.; Wesemann, J.; Woodruff, W. "Solution Studies of Ru2(O2CR)4n+ Complexes ( $n=0,1$; $\mathrm{O} 2 \mathrm{CR}=$ Octanoate, Crotonate, Dimethylacrylate, Benzoate, $\mathrm{p}$-Toluate) and Solid-State Structures of Ru2(O2C-p-tolyl)4(THF)2, [Ru2(O2C-p-tolyl)4(THF)2]+[BF4]-, and Ru2(O2C-p-tolyl)4(CH3CN)2: Investigations of the Axial Ligation of the Ru2 Core" Inorg. Chem., 35(12), 3643-3658 (1996).

3. James, C.; Morris, D.; Doorn, S.; Arrington, C.; Dunbar, K.; Finnis, G.; Pence, L.; Woodruff, W. "Photochemistry of deca(acetonitrile) dirhodium(II) cation: evidence for kilosecond-lived photoinduced charge separation". Inorg. Chim. Acta, 242(1-2), 91-6 (1996).

4. Abney, K.; Eller, P.; Eastman, M.; Pace, C.; Kinkead, S.; Kissane, R.; Woodruff, W. "Thermal decomposition reactions of gaseous dioxygen difluoride and dioxygen fluoride at ambient temperature". J. Fluorine Chem., 73(2), 137-46 (1995). 